\title{
El concepto de orden público como causal de nulidad de un laudo tratándose de un arbitraje comercial internacional
}

\author{
Juan Carlos Marín González* \\ Rolando García Mirón**
}

\begin{abstract}
RESUMEN
La presente investigación se enfoca en el análisis del concepto de orden público como causal de nulidad de un laudo tratándose de un arbitraje comercial internacional. El estudio inicia con una descripción de las principales características del arbitraje en Chile en sus dos versiones: nacional e internacional. Posteriormente se identifican y explican los tres principios rectores del arbitraje internacional que lo distinguen del arbitraje nacional, a saber, pleno respeto a la autonomía de las partes, plena libertad del árbitro para desarrollar el respectivo procedimiento y acotada intervención de la judicatura local. La segunda sección de la investigación se dedica al estudio del concepto de orden público como causal de nulidad de laudos internacionales. En este apartado se describen los elementos que tanto la doctrina como los tribunales de diversas jurisdicciones han identificado en su esfuerzo por delimitar el significado de este concepto.
\end{abstract}

Arbitraje internacional - causal de nulidad - orden público

\section{The concept of public order as bases for annulment of an award in the case of international commercial arbitration}

\begin{abstract}
This research focuses on analyzing the concept of public order as bases for annulment of an award in the case of international commercial arbitration. The study begins with a description of the main features of arbitration in Chile in two versions: national and international. Subsequently, the three guiding principles of international arbitration that distinguish it from domestic arbitration are identified and explained, namely, full respect for the autonomy of the parties, the arbitrator complete freedom to develop the relevant procedure and the limited intervention of the local judiciary. The second section of the research is devoted to studying the concept of public order as bases for annulment of international awards. This section describes the elements that both the doctrine and the courts in various jurisdictions have identified in their effort to define the meaning of the concept.
\end{abstract}

International arbitration - bases of annulment - public order

* Abogado, Doctor en Derecho, Profesor e investigador del Instituto Tecnológico Autónomo de México (ITAM); Ciudad de México. jcmarin@itam.mx

** Licenciado en Derecho, Magíster en Derecho, rolando.garcia.miron@gmail.com

Artículo recibido el 30 de marzo de 2011 y aceptado para su publicación por el Comité Editorial el 27 de mayo de 2011. 


\section{INTRODUCCIÓN}

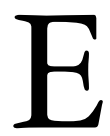

l arbitraje como forma de resolver las disputas entre partes se encuentra de moda. Cada día más autores se suman a sus filas. Hasta hace poco en Chile no había más que un libro dedicado a esta materia. Su propio autor ha expresado la sorpresa que le ha causado el prolongado éxito de su monografía. Hoy en día, en cambio, se pueden encontrar tres o cuatro libros dedicados a tratar el arbitraje. Todos publicados en el último lustro. Si bien esto puede resultar menor en un país que cuente con una cultura jurídica desarrollada, para Chile es un notable logro.

Lo anterior parece ser, en todo caso, un fenómeno común en los países de Iberoamérica. Como ha expresado Yves Derains, "Durante mis años de trayectoria en la Cámara de Comercio Internacional, en los años setenta, América Latina era una tierra de misión para el arbitraje. Un panorama desierto -aunque ya explorado- en la materia en razón de la influencia adversa de los códigos napoleónicos y del largo y férreo reinado de los procesalistas. La gran mayoría de ellos se oponían al arbitraje e irónicamente, aquella pequeña minoría que se presentía como favorable constituía un peligro mayor, ya que transformaba el procedimiento arbitral en algo aún más complicado que un proceso judicial. Conferencias sobre el arbitraje se organizaban de vez en cuando, con la participación de pocos aficionados cuyo entusiasmo excusaba la ignorancia. [...] Este año de 1975 fue un año de transición. Es el año de la adopción de la Convención Interamericana de Panamá sobre arbitraje internacional, un paso importante, junto con la Convención de Nueva York, en el camino que llevó a las circunstancias que rodean al arbitraje hoy, tan diferentes. Todos los Estados latinoamericanos son signatarios de la Convención de Nueva York, así como casi todos cuentan con legislaciones modernas en la materia. La primera Conferencia Latinoamericana de Arbitraje, que tuvo lugar en Asunción, en junio de 2009, contó con la asistencia de mil participantes con representantes de toda la región" 1 .

Existe en materia de arbitraje un concepto que puede transformarse, por paradójico que ahora pueda resultar, en la llave que defina el éxito o el fracaso de este valioso instrumento de solución de controversias en Iberoamérica. Este concepto es el de orden público. El éxito o fracaso dependerá de la aplicación que los tribunales nacionales hagan del mismo. De allí que el presente trabajo -que se divide en dos partes, una dedicada a la regulación del arbitraje comercial internacional en Chile, la otra a analizar el concepto de orden público- busque dar algunas luces en la forma como los tribunales chilenos deberían interpretarlo.

${ }^{1}$ Yves Derains, Prefacio de la obra coordinada por Conejero Roos, Cristian; Hernández-Mora, Antonio; Macchia, Valeria y Soto, Carlos, El arbitraje comercial internacional en Iberoamérica, Legis, Colombia, 2009, p. 47. 


\section{Regulación del arbitraje comercial internacional en Chile}

En Chile actualmente coexisten dos sistemas de arbitraje. El nacional, por un lado, y el comercial internacional, por el otro. En términos generales, el primero se rige por las disposiciones pertinentes del Código Orgánico de Tribunales (COT) y del Código de Procedimiento Civil (CPC). El segundo, en cambio, por la Ley No $19.971^{2}$.

Si bien ambos sistemas de arbitraje tienen similar propósito -resolver un litigio entre partes- sus divergencias no son menores. "La diferencia entre ambas manifestaciones proviene del ámbito de aplicación y de ciertos elementos que le dan su razón de ser al arbitraje comercial internacional, a saber: la posibilidad de aplicar un derecho de fondo distinto del país donde se sigue el arbitraje, la admisión de extranjeros como árbitros en la decisión del conflicto, la existencia de un sistema de ejecución del laudo amparado por convenciones internacionales, entre otros aspectos"3.

En este contexto, debemos tener presente que la Ley $\mathrm{N}^{\circ} 19.971$ encuentra su antecedente inmediato en la Ley Modelo de Arbitraje de la UNCITRAL -aprobada por la Asamblea General de la ONU el 11 de diciembre de 1985-, cuyo objetivo fue homologar los procedimientos arbitrales internacionales a nivel global. La nueva ley chilena sobre Arbitraje Comercial Internacional, se ha dicho, incorporó a Chile "al círculo de países que han adoptado en su ordenamiento interno la Ley Modelo de Arbitraje de la Comisión de las Naciones Unidas para el Derecho Mercantil Internacional (CNUDMI), más conocida en inglés como UNCITRAL de 1985, respondiendo de esta forma a la tendencia moderna de armonización del derecho de arbitraje comercial internacional" 4 .

De esta forma, la Ley Modelo de la UNCITRAL se ha incorporado al ordenamiento jurídico chileno por medio de la Ley $\mathrm{N}^{\circ} 19.971$, cuya fuerza legal es equivalente a las reglas legales que regulan el arbitraje doméstico, pero con un ámbito de aplicación más reducido, cual es, sólo para arbitrajes comerciales internacionales definidos de conformidad con el artículo 1 de dicha ley.

Su propósito y sus ventajas son muy claras: convertir a Chile en un centro de arbitraje importante en el mundo, especialmente en América Latina ${ }^{5}$, y contribuir a dar una imagen de seriedad y confianza de Chile ante la comunidad jurídica y empresarial

${ }^{2}$ Esta ley fue publicada en el Diario Oficial el 29 de septiembre de 2004. A su respecto, la doctrina nacional expresó: "En el año 2004, la Ley N ${ }^{\circ} 19.971$ incorporó al derecho chileno la Ley Modelo de la UNCITRAL sobre el arbitraje comercial internacional. Con ello fue creado un sistema dualista, en el cual cada una de las dimensiones del arbitraje cuenta con una regulación propia”. Mereminskaya, E., “Arbitraje doméstico e internacional en Chile: en búsqueda de la armonía”, en Vargas, J. E. y Gorjón, F. J. (coord.), Arbitraje y Mediación en las Américas, Centro de Estudios de Justicia de las Américas, Universidad Autónoma de Nuevo León, México, 2006, p. 97.

3 Romero Seguel, A. y Díaz, J.I., El arbitraje interno y comercial internacional, LexisNexis, Santiago, 2007 , p. 7.

${ }^{4}$ Figueroa Valdés, J.E., "La nueva ley chilena sobre arbitraje comercial internacional", en Gaceta Jurídica, núm. 303, 2005, p. 8.

${ }^{5}$ Historia legislativa, Informe de la Comisión de Relaciones Exteriores, sesión 58, 18 de mayo de 2004 . 
internacional, pues brinda seguridad jurídica para inversionistas y contrapartes extranjeras; fomenta las transacciones comerciales y la inversión extranjera; crea un régimen jurídico aplicable a la resolución de controversias internacionales que se producen entre particulares; genera confianza para que Chile sea sede de arbitrajes comerciales internacionales; contribuye a la proliferación y perfeccionamiento de los servicios de arbitraje comercial internacional ofrecidos por las entidades arbitrales chilenas; y permite que las pequeñas y medianas empresas chilenas, que celebran contratos con contrapartes extranjeras, puedan acudir a esta figura en Chile ${ }^{6}$.

La referida ley se inspira en tres principios que son claves en el entendimiento de esta materia. Estos tres grandes principios que informan el arbitraje comercial internacional y que no suelen tener aplicación en el arbitraje doméstico, o cuyo alcance es muy acotado, son los siguientes:

A. Pleno respeto de la autonomía de las partes.

B. Plena libertad del árbitro para desarrollar el respectivo procedimiento.

C. Acotada intervención de la judicatura local.

Sobre la plena operatividad y aplicación de estos tres principios al arbitraje comercial internacional existe pleno acuerdo, tanto en la doctrina (nacional y comparada) como en la jurisprudencia (nacional y extranjera). La historia legislativa de la Ley $\mathrm{N}^{\circ} 19.971$ avala esta posición ${ }^{7}$.

\section{A. Pleno respeto de la autonomía de las partes}

Un importante principio de la ley chilena consiste en reconocer a las partes la libertad para acomodar la forma en que debe tramitarse el arbitraje comercial internacional. Las partes tienen amplia libertad para acordar los procedimientos arbitrales e, incluso, pueden formular ellas mismas las reglas de procedimiento.

Lo ordinario es que las partes incorporen en el compromiso un conjunto uniforme de reglas de arbitraje, como la normativa de UNCITRAL sobre la materia o el mismo Reglamento de la Cámara Internacional de Comercio (ICC por sus siglas en inglés). Asimismo, las partes pueden complementar estas reglas procesales uniformes con otras que tengan mayor extensión que aquéllas en algunos aspectos, o que se adapten mejor a sus circunstancias particulares.

Sobre este punto existe acuerdo a nivel doctrinal: "A diferencia de lo que ocurre con los procedimientos en el arbitraje nacional, que están regulados en diversos textos legales y reglamentarios, el arbitraje comercial internacional tiene como fuente la autonomía de la

${ }^{6}$ Cfr. Urrejola Monckeberg, S., "Chile debe contar con una ley de Arbitraje Internacional”, en Boletín Jurídico, Ministerio de Justicia, núm. 6, 2004, p. 109 y ss.

${ }^{7}$ Sobre este último punto véase Sateler, R., "Historia de la Ley N 19.971 sobre arbitraje comercial internacional”, en Picand Albónico, E. (coord.), Estudios de Arbitraje, libro homenaje al profesor Patricio Aylwin Azócar, Editorial Jurídica de Chile, Chile, 2007, pp. 377-389. 
voluntad de los contratantes. En el caso del arbitraje ad hoc, la autonomía permite a las partes crear las normas jurídicas por las cuales se regirá el procedimiento. Tratándose de arbitraje institucional, las partes en su acuerdo arbitral se remiten a un reglamento específico, que regula la conducción del procedimiento arbitral; existen varios instrumentos de esta naturaleza, como ya tuvimos oportunidad de señalarlo precedentemente" 8 . (Énfasis añadido).

De esta forma, en el sistema de arbitraje internacional existen diversos conjuntos de reglas procesales que han permitido estandarizar los procedimientos de arbitraje internacional. Los ejemplos más comunes son las reglas UNCITRAL e ICC. Mientras las de UNCITRAL son utilizadas en procedimientos arbitrales ad hoc, las reglas ICC son institucionales. Esto significa que las reglas procesales ICC regulan los procedimientos que se tramitan al alero de la misma Cámara Internacional de Comercio. Así, la autonomía de la voluntad en arbitraje internacional permite a las partes someterse al sistema de reglas procesales que estimen más adecuado para tramitar una eventual controversia de arbitraje internacional, y al mismo tiempo poder pactar o crear otras reglas que estimen convenientes a fin de complementar el sistema de reglas que hayan acordado. Las partes, por tanto, gozan de una amplia libertad en esta materia.

Ahora bien, la Ley $\mathrm{N}^{\circ} 19.971$ recoge este principio general del arbitraje internacional consistente en la libertad de las partes para acordar las reglas procesales que estimen apropiadas en su artículo 19.1) al establecer que:

"Determinación del procedimiento.

1) Con sujeción a las disposiciones de esta ley, las partes tendrán libertad para convenir el procedimiento a que se haya de ajustar el tribunal arbitral en sus actuaciones".

Este principio de la autonomía de la voluntad se encuentra presente a lo largo de toda la Ley $\mathrm{N}^{\circ} 19.971$, en donde se aplica respecto de distintas instituciones, tales como: 1) las reglas de recepción de comunicaciones escritas (artículo 3); 2) número de árbitros (artículo 10); 3) nombramiento de los árbitros (artículo 11); 4) procedimiento de recusación (artículo 13); 5) facultad para ordenar medidas provisionales (artículo 17); 6) ampliación de la demanda o contestación (artículo 23); 7) celebración de audiencia (artículo 24); 8) procedencia de la rebeldía (artículo 25); 9) nombramiento de peritos (artículo 26), entre otras.

\section{B. Plena libertad del árbitro para desarrollar el respectivo procedimiento}

En el arbitraje comercial internacional el árbitro goza de plena libertad para la tramitación del arbitraje sometido a su conocimiento. Esto significa que el árbitro tiene

${ }^{8}$ Sandoval López, R., "La normativa de Uncitral sobre arbitraje comercial internacional como instrumento de unificación", en Picand Albónico, E. (coord.), Estudios de Arbitraje, libro homenaje al profesor Patricio Aylwin Azócar, Editorial Jurídica de Chile, Chile, 2007, p. 503. 
libertad para suplir la voluntad de las partes en todas aquellas materias procesales en las cuales exista silencio de ellas.

De conformidad con la Ley $\mathrm{N}^{\circ} 19.971$ el árbitro puede conducir el arbitraje de la manera que lo estime más apropiado (artículo 19 de la ley). El poder discrecional del árbitro incluye la facultad de determinar la admisibilidad, el valor probatorio, el peso y la producción de la prueba, según lo previsto en el mismo artículo.

Asimismo, la Ley $\mathrm{N}^{\circ} 19.971$ contiene una serie de reglas adjetivas supletorias del silencio de los litigantes, que abarcan todo el espectro en el que se desenvuelve el procedimiento arbitral, desde su inicio hasta el pronunciamiento del laudo.

De esta forma la Ley $\mathrm{N}^{\circ} 19.971$ combina la libertad de las partes para elegir las normas aplicables al procedimiento arbitral, con un conjunto de reglas supletorias, -que no tienen carácter imperativo- y que permiten al tribunal arbitral conducir el arbitraje con independencia de las reglas locales, que regulan el procedimiento en un arbitraje doméstico? 9

Así el artículo 19 2) de la Ley $\mathrm{N}^{\circ} 19.971$ señala:

“Determinación del procedimiento.

[... 2) A falta de acuerdo, el tribunal arbitral podrá, con sujeción a lo dispuesto en esta ley, dirigir el arbitraje del modo que considere apropiado. Esta facultad conferida al tribunal arbitral incluye la de determinar la admisibilidad, la pertinencia y el valor de las pruebas".

Como se puede apreciar, el tribunal arbitral, al alero de esta normativa, puede llevar adelante el arbitraje comercial internacional prescindiendo de las normas procesales que reglamentan el arbitraje local. Lo anterior produce un efecto favorable pues permite que los tribunales "puedan adoptar las características del procedimiento con que las partes (y ellos mismos) estuvieran familiarizadas o fuesen al menos aceptables para ellas. [... Esta discrecionalidad en cuanto al procedimiento en todos estos casos parece ir encaminada a facilitar el arbitraje comercial internacional, mientras que verse forzado a aplicar la ley del país donde el arbitraje tiene lugar, plantearía una importante desventaja a las partes que no están acostumbradas con ese sistema concreto, y posiblemente peculiar, de procedimiento y presentación de pruebas" ${ }^{10}$.

La prescindencia de las normas locales de arbitraje y de procedimiento, como las contenidas en el COT y el CPC, fue esencial en la adopción de la Ley N N 19.971. Esta es la única manera de permitir la adecuada internacionalización del arbitraje. Lo contrario supondría imponerle a las partes reglas de procedimiento que les son ajenas, reglas procesales altamente técnicas que no les son familiares, lo que entrabaría y dificultaría el arbitraje. Por otro lado, si se exigiera la aplicación de las reglas procesales locales de la

\footnotetext{
${ }^{9}$ Ibidem, p. 495.

${ }^{10}$ Figueroa Valdés, J. E., op. cit., nota 4, pp. 12-13.
} 
sede del arbitraje, se les impondría a los árbitros extranjeros la carga de hacerse expertos en un derecho foráneo para poder conducir un arbitraje, lo que no parece tan razonable.

En definitiva, la ley chilena sobre Arbitraje Comercial Internacional -y en verdad la de los más de 40 países que han adoptado la Ley Modelo de la UNCITRAL- contiene un procedimiento muy dúctil y flexible, que prescinde absolutamente de las más bien rígidas disposiciones del arbitraje doméstico, y de las reglas procesales locales del país sede del arbitraje.

\section{Acotada intervención de la judicatura local}

Constituye un principio básico del desarrollo del arbitraje comercial internacional la limitación de la intervención judicial durante el arbitraje, siendo uno de los elementos esenciales para comprender a cabalidad tanto la Ley $\mathrm{N}^{\circ} 19.971$ como la Ley Modelo de la UNCITRAL.

La doctrina nacional ha señalado que "una de las diferencias más profundas entre el arbitraje interno y el internacional está en el sistema de recursos. [...] Sin perjuicio de su desarrollo posterior, uno de los mayores aciertos técnicos de la Ley de Arbitraje Comercial Internacional (LACI) está en su sistema de impugnación mediante una acción de nulidad. Las causales de impugnación abarcan todos los aspectos relativos al arbitraje, esto es, comprenden desde la regularidad del procedimiento arbitral, las exigencias de validez del convenio y el control frente a excesos que vulneran el orden público chileno. Mediante esta posición se busca dar certeza y estabilidad a la decisión arbitral, impidiendo el ejercicio de acciones que indirectamente pretendan revertir el resultado de proceso arbitral" 11. (Énfasis añadido).

De este modo, la Ley $\mathrm{N}^{\circ} 19.971$ otorga independencia al árbitro en cuanto a las resoluciones por él dictadas a diferencia de lo que acontece en el plano interno, donde los tribunales judiciales tienen un amplio margen para la revisión de las resoluciones pronunciadas en sede doméstica, según lo disponen los artículos 239 de COT y 242 del CPC. En tal sentido, se reconoce como principio básico del instituto arbitral la limitada actuación de los tribunales estatales en el procedimiento arbitral, conocido como el "principio de intervención mínima".

El artículo $5^{\circ}$ de la Ley $\mathrm{N}^{\circ} 19.971$ recoge lo anterior al señalar "en los asuntos que se rijan por la presente ley no intervendrá ningún tribunal, salvo en los casos que la ley así lo disponga", y el artículo 34 de la Ley que consagra a "la petición de nulidad como único recurso contra el laudo arbitral”. (Énfasis añadido).

Descrito brevemente el contexto en el que se desenvuelve y aplica la Ley No 19.971, corresponde, a continuación, entrar de lleno en el análisis del concepto de orden público como causal que permite pedir la nulidad de un laudo al alero de la referida normativa legal.

${ }^{11}$ Romero Seguel, A., "Principales diferencias entre el arbitraje interno y el arbitraje internacional en el ordenamiento chileno", en Romero Seguel, A. (coord.), Estudios de derecho en homenaje a Raúl Tavolari Oliveros, LexisNexis, Santiago, 2007, p. 207. 


\section{CONCEPTO DE ORDEN PÚBLICO}

$\mathrm{Al}$ abordar este punto es necesario tener presente que el concepto de orden público es uno de los más vaporosos y difíciles de precisar en el ámbito jurídico. Como señalan destacados juristas, es un concepto que varía de tiempo en tiempo y de lugar en lugar. Gráficamente se ha dicho que: "El orden público es un caballo difícil de domar; aun logrando montarlo, no sabe uno adónde lo va a conducir. Puede alejar del buen derecho. Nunca es argumentado más que cuando los demás puntos fallan"12. Siguiendo con esta idea, otros autores se han referido al orden público como un camaleón empedernido que constantemente cambia de apariencia ${ }^{13}$. Ambos ejemplos resaltan la opinión común de quienes forman parte del mundo del arbitraje ya sea como árbitros, abogados, jueces o académicos, a saber, que lo vaporoso del concepto de orden público lo convierte en una constante amenaza a la certeza jurídica y a la predictibilidad de las resoluciones judiciales respecto a los laudos.

\section{A. Antecedentes}

Fruto de lo anterior fue el hecho de que al discutirse al interior de la UNCITRAL la redacción del artículo 34 (2)(b)(ii) -disposición adoptada de manera idéntica por la Ley No 19.971- varios de los participantes argumentaron a favor de suprimir la expresión "orden público" dada su notable vaguedad, entre otros problemas ${ }^{14}$. "Al examinar dicho concepto, quedó entendido que el mismo no equivalía a la posición política o a la política internacional de un Estado, sino que abarcaba los conceptos y principios fundamentales de justicia. Se señaló que en algunos ordenamientos de tradición anglosajona ese término podría ser interpretado en el sentido de no incluir los principios de justicia procesal. Sin embargo, la Comisión estuvo de acuerdo en que debía conservarse ese apartado, ya que todos los sistemas de tradición de 'derecho civil' están inspirados en el concepto francés de 'ordre public', en el que se consideran contenidos de los principios de justicia procesal; igualmente que su inserción en muchos tratados abarca los principios de legislación y justicia. Luego de deliberar, la Comisión acordó conservar esta causal, señalando que la expresión 'orden público', que había sido utilizada en la Convención de Nueva York de 1958 y en otros muchos tratados, abarcaba principios fundamentales de legislación y justicia tanto en el aspecto sustantivo como en el de procedimiento. Así, ciertos casos como la corrupción, el soborno, o el fraude y otros graves análogos constituirían un motivo de anulación"15. (Énfasis añadido).

12 Burrough J., en Richardson v. Mellish, 2 Bing. 229 (1824), p. 303, citado por González de Cossío, F., El arbitraje y la judicatura, Porrúa, México, 2007, p. 60.

${ }^{13}$ Cfr. Arfazadeh, H., "In the Shadow of the Unruly Horse: International Arbitration and the Public Policy Exception”, en The American Review of International Arbitration, Vol. 13, 2002, p. 43.

${ }^{14}$ Cfr. Born, G., International Commercial Arbitration, tomo II, Kluwer Law International, Países Bajos, 2009, pp. 2620-2621, en particular la nota 352.

${ }^{15}$ Informe oficial de la CNUDMI sobre el $18^{\circ}$ período de sesiones de la Asamblea General, p. 38, citado por Picand Albónico, E., El arbitraje comercial internacional, tomo I, Editorial Jurídica de Chile, Chile, 2005, pp. 346-347. 


\section{B. Concepto}

De esta forma, como lo demuestran las discusiones durante el proceso de elaboración de la Ley Modelo, parece haber acuerdo general en la doctrina y en las resoluciones de los tribunales en que la causal de nulidad contenida en el artículo 34 (2)(b)(ii) -retomada por la Ley $\mathrm{N}^{\circ} 19.971$ - se refiere a "las nociones más básicas de moralidad y de justicia de un sistema jurídico" ${ }^{16}$. Sobre este mismo punto es posible citar lo que han señalado diversos tribunales que se han pronunciado al respecto. Por ejemplo, la Corte de Apelaciones de París estableció que el orden público se refiere a los principios de importancia fundamental para el sistema jurídico ${ }^{17}$. Por su parte, el Tribunal Federal Suizo señaló que el orden público se refiere a las nociones más básicas de justicia en Suiza, así como al sistema de valores fundamentales de aquella nación ${ }^{18}$. Finalmente, lo dicho por la Corte de Apelaciones del Segundo Circuito en Estados Unidos parece resumir de forma adecuada los elementos destacados por otros tribunales y la doctrina al precisar que "[l]a ejecución de un laudo internacional sólo puede negarse cuando dicha ejecución violaría las nociones más básicas de moralidad y justicia del Estado”19.

Si bien lo señalado en los párrafos anteriores permite empezar a trazar el contorno del concepto de orden público, resulta evidente que ante la vaguedad de la definición existente desde la doctrina se haya señalado que "el uso de la teoría del orden público es potencialmente impredecible y expansiva" ${ }^{20}$. De la misma forma, algunos tribunales han advertido de las complicaciones a las que se enfrentan cuando intentan asir este concepto. Por ejemplo, en una resolución la Primera Sala Civil del Tribunal Federal Suizo, después de alegar falta de acuerdo en la doctrina respecto al significado de este concepto, expresó lo siguiente: "Este breve recuento del concepto de orden público demuestra, una vez más, que en cierta manera es inasible" ${ }^{21}$.

La preocupación parece justificada. ¿Cuáles son los principios más básicos de moralidad y justicia de un ordenamiento jurídico? ¿Cuáles son los valores centrales de un ordenamiento jurídico? ¿A través de qué método se pueden determinar estos principios? ¿Se trata de los mismos principios en los diferentes sistemas jurídicos? Todas estas interrogantes no encuentran respuesta en la definición ordinaria de orden público. Ante esta situación, son muchos los autores que advierten del riesgo latente que este concepto implica para el arbitraje internacional, ya que inserta un elemento de incertidumbre en

${ }^{16}$ González de Cossío, F., Arbitraje, Porrúa, México, 2004, p. 429.

${ }^{17}$ Cfr. SA Thales Air Défense v. Euromissile, Sentencia de la Corte de Apelaciones de París de 18 de noviembre de 2004.

${ }^{18}$ Cfr. Tribunal Federal Suizo, Sentencia de 30 de diciembre de 1994 citado por Born, G., International Arbitration. Cases and Materials, Aspen Publishers, EUA, 2011, pp. 1082-1097.

${ }^{19}$ Parsons \& Whittemore Overseas Co., Inc., v. Société Generale de l'Industrie du Papier, 508 F2d 969, sentencia de la Corte de Apelaciones del Segundo Circuito de 23 de diciembre de 1974. La traducción es nuestra.

${ }^{20}$ Born, G., op. cit., nota 14, p. 2625. La traducción es nuestra.

21 Tensaccia S.P.A. v. Freyssinet Terra Armata R.L., Primera Sala Civil del Tribunal Federal Suizo, sentencia de 8 de marzo de 2006. La traducción es nuestra. 
uno de los puntos más delicados de este procedimiento, a saber, la eficaz ejecución de los laudos. Mientras que uno de los principales objetivos del arbitraje internacional es promover la certeza, la celeridad y la uniformidad en la resolución de controversias, el orden público parece estar en constante oposición con este objetivo ${ }^{22}$.

Ahora bien, pese a las dificultades reseñadas, hay elementos que, fruto de los años de discusión y trabajo - tanto a nivel doctrinal y jurisprudencial, nacional y comparada-, han adquirido un grado importante de consenso, al menos en lo que el concepto de orden público debería significar como motivo de anulación (o de no ejecución) de un laudo internacional ${ }^{23}$. A continuación se describirán los elementos más relevantes.

\section{Las dos dimensiones del orden público}

En primer lugar, la doctrina ha reconocido que el orden público es un concepto que tiene dos dimensiones, a saber, una procesal y una sustantiva. "[L]os principios fundamentales de justicia y moralidad son esencialmente aquellos que [...] se consideran necesarios para la protección, primero, de los derechos procesales fundamentales de las partes en el procedimiento arbitral y, segundo, los derechos contractuales fundamentales de las partes en transacciones internacionales" 24 .

En su ensayo Homayoon Arfazadeh identifica los principales elementos que los tribunales en general han reconocido como componentes del orden público. Así, el orden público procesal cubre lo que tradicionalmente se denomina como debido proceso, en particular "el derecho de las partes a ser debidamente llamadas al arbitraje, igualdad en el trato, un procedimiento adversarial (que incluye el derecho a ser oído), la prohibición de parcialidad y la falta de independencia, fraude o corrupción por parte de los árbitros [y el principio de cosa juzgada]" 25 . Por su parte, el orden púbico sustantivo incluye elementos como "el deber de actuar de buena fe, la prohibición de abuso de derecho, prohibición de discriminación, prohibición de expropiación sin un debido proceso [...] y la protección de los incapaces" 26 .

Es importante recordar que la lista anterior no pretende ser exhaustiva ni permanente. Simplemente señala los elementos que con mayor frecuencia los tribunales y la doctrina consideran incluidos en el concepto de orden público. Sin embargo, como se explicará más adelante, parece existir una deseable tendencia por parte de los tribunales para no incorporar más elementos a los antes señalados. De igual forma, si bien estos

${ }^{22}$ Cfr. Arfazadeh, H., op. cit., nota 13, p. 44.

${ }^{23} \mathrm{Si}$ nos detenemos un momento en este punto, podremos apreciar que las causales que permiten pedir la nulidad de un lado, previstas en el artículo 34 de la Ley $\mathrm{N}^{\circ} 19.971$, son exactamente las mismas que se regulan para oponerse a su ejecución, según lo dispone el artículo 36 de la misma Ley. De ello parece evidente que por simple economía procesal, y con el fin de evitar sentencias contradictorias, una vez que la Corte de Apelaciones respectiva declara la validez del laudo porque no se actualizan las causales del referido artículo 34, no puede, posteriormente, acoger alguna causal por el mismo motivo de no ejecución del mismo.

${ }^{24}$ Arfazadeh, H., op. cit., nota 13, pp. 48-49. La traducción es nuestra.

${ }^{25}$ Ibídem, p. 49. La traducción es nuestra.

${ }^{26}$ Ibídem, p. 50. La traducción es nuestra. 
elementos facilitan un concepto uniforme de orden público a través de los diferentes sistemas jurídicos, es natural observar ligeras variaciones en el contenido específico de cada uno de ellos, producto de las diferencias culturales que existen entre las diversas naciones ${ }^{27}$. Estas variaciones no presentan mayor problema para la eficaz ejecución de los laudos siempre que se mantengan en un nivel bajo.

Como puede observarse, desde la doctrina y desde los tribunales se han hecho importantes esfuerzos para delimitar con la mayor precisión posible el concepto de orden público y evitar que ese "caballo difícil de domar" termine por destruir la razón de ser del arbitraje: la resolución de controversias con la mayor celeridad y certeza posible. Sin embargo, un análisis de los elementos que conforman las diferentes subcategorías del orden público demuestra que incluso estos elementos padecen un importante nivel de vaguedad y una inherente fuerza expansiva. Si bien el uso de estas subcategorías ayuda a reducir el carácter vaporoso del orden público, éstas no son lo suficientemente rígidas como para eliminar el riesgo que se ha mencionado. Por esa razón, desde la doctrina se ha considerado necesario complementar una definición detallada del orden público con una serie de principios interpretativos que sirvan de guía a los tribunales y les ayuden a mantener en todo momento al caballo bajo control.

A continuación se describirán los tres principios interpretativos más relevantes que deben servir como guía a los tribunales que se enfrenten a casos en los que se solicite la nulidad de un laudo por ser éste contrario al orden público.

\section{Excepcionalidad}

En primer lugar se debe señalar el denominado principio de excepcionalidad, que refiere que debe respetarse el principio de cosa juzgada de los laudos dictados en el contexto del arbitraje comercial internacional, a menos que exista una circunstancia muy excepcional que lo impida. Principio que ha sido aplicado expresamente por los tribunales en el derecho comparado. Así, por ejemplo, la Corte Europea de Justicia en una sentencia del año 1999 decidió que: "las exigencias relativas a la eficacia del procedimiento arbitral justifican que el control de los laudos arbitrales tenga carácter limitado y que sólo pueda obtenerse la anulación de un laudo o la denegación del reconocimiento en casos excepcionales" 28 . En efecto, si uno de los principales objetivos del arbitraje como método de solución de controversias es obtener, con la mayor celeridad posible, una resolución que ponga fin de forma definitiva a una disputa entre las partes, el principio de cosa juzgada debe ser la regla general y las declaratorias de nulidad excepciones muy limitadas ${ }^{29}$.

De esta forma, si en el arbitraje la regla general debe ser que los tribunales den plena eficacia a los laudos, es fundamental que la causal de nulidad por violación del orden público sea utilizada por los tribunales únicamente en situaciones extraordinarias.

${ }^{27}$ Cfr. Arfazadeh, H., op. cit., nota 13, pp. 50-51.

${ }^{28}$ Eco Swiss China Time Ltd. Vs. Benetton International NV, Caso C-126/97, sentencia del Tribunal de Justicia de 1 de junio de 1999.

${ }^{29}$ Cfr. Born, G., op. cit., nota 14, pp. 1047-1060. 
Al respecto, la doctrina señala que en las naciones donde el arbitraje internacional ha logrado un mayor desarrollo los tribunales han reconocido la excepcionalidad de esta causal de nulidad y sólo han anulado laudos por ser contrarios al orden público en casos limitados y excepcionales ${ }^{30}$. Esto es, los tribunales han limitado esta causal a casos en los que existe una auténtica contradicción entre el laudo y el orden público de ese país y no cuando el juzgador se encuentra en desacuerdo con la decisión del tribunal arbitral respecto al fondo de la controversia ${ }^{31}$.

De una forma muy gráfica se podría decir que el orden público como causal de nulidad establece un estándar muy elevado que sólo se rebasa en los casos más graves. Es importante señalar que el tribunal que conoce de la solicitud de nulidad no está llamado a pronunciarse nuevamente sobre el fondo de la controversia. Ésta ya fue sometida por las partes a la determinación de un tribunal arbitral. La función del tribunal se limita (en el caso de una acción de nulidad por violentar el orden público) a evaluar si el laudo se opone a los principios más elementales de moralidad y justicia de un determinado sistema jurídico. Lo que se busca es evitar dar efectos jurídicos a laudos que se encuentran en evidente conflicto con los principios mencionados, no otorgar a la parte que se opone a la ejecución del laudo una segunda oportunidad para exponer sus argumentos respecto al fondo de la controversia.

En una resolución de gran importancia para el arbitraje internacional, la Corte Suprema de Estados Unidos dejó en claro que en ese país la causal de nulidad por violación al orden público no faculta a los tribunales para ejercer un poder de revisión amplio sobre los laudos impugnados ${ }^{32}$. La Corte fue muy clara al señalar que la facultad de revisión de los tribunales se limita a los casos más evidentes de violación del orden público $^{33}$.

En síntesis, las características del arbitraje requieren darle la mayor eficacia posible a los laudos. Por lo tanto, el principio de cosa juzgada aplicado a los laudos debe ser la regla general. Los tribunales deben ser muy cuidadosos al evaluar si un laudo es contrario al orden público y limitar esta causal a aquellos casos de evidente conflicto entre el laudo y los principios básicos de moralidad y justicia del sistema jurídico como hemos visto.

\section{E. Interpretación restrictiva}

El segundo principio que debe guiar a los tribunales al interpretar el alcance del orden público es el de interpretación restrictiva. Como ya se mencionó, tanto el concepto

\footnotetext{
${ }^{30}$ Cfr. Ibidem, p. 2625.

${ }^{31}$ Cfr. Idem.

32 Cfr. United Paperworkers Int'l Union v. Misco Inc, 484 U.S. 29, sentencia de la Corte Suprema de Estados Unidos de América de 1 de diciembre de 1987. Es importante señalar que si bien en Estados Unidos la ley arbitral local no contempla una causal específica de nulidad de laudos por violación al orden público (public policy) los tribunales han reconocido que esta causal es parte de los principios de la tradición

${ }^{33}$ Cfr. Idem.
} del common law. 
de orden público en general como cada uno de los elementos que lo componen poseen una fuerza expansiva que invita a los juzgadores a ampliar el alcance de esta causal de nulidad. Frente a este riesgo, es fundamental que los tribunales mantengan una gran disciplina interpretativa y eviten incorporar nuevas categorías al concepto de orden público. Así lo señala Homayoon Arfazadeh quien advierte que por ser éstos principios de un gran nivel de abstracción lo recomendable es interpretarlos y construirlos de forma restrictiva ${ }^{34}$.

En caso contrario, el riesgo que se corre no es menor. Una interpretación extensiva de este concepto por parte de la judicatura local atentaría contra la idea misma del arbitraje comercial internacional, y otorgaría incentivos perversos a quienes no quieran cumplir con las obligaciones que en el ámbito de los negocios internacionales hubieren contraído. Esto ya ha sucedido en otras latitudes: "Al terminar la época dorada del cumplimiento voluntario de las sentencias arbitrales por las empresas estatales soviéticas, han surgido tácticas obstructivas al arbitraje. Dado que la justicia rusa no había elaborado un concepto operativo de orden público, éste se ha transformado en la defensa favorita de las partes que buscan atacar la eficacia de los laudos arbitrales. Se observa con preocupación que el recurso al orden público tenga en Rusia mayor acogida de lo que el consenso internacional podría considerar apropiado"35. En este mismo sentido, pero comentando el caso de México, desde la doctrina se ha señalado que invocar una violación al orden público es la estrategia más utilizada por los litigantes que desean conseguir la anulación de un laudo ${ }^{36}$.

Dada la naturaleza inestable del concepto de orden público, las partes que busquen lograr la nulidad del laudo argumentarán que éste se encuentra en contradicción con los principios fundamentales del orden público. Sólo la disciplina interpretativa de los tribunales puede limitar la eficacia de esta estrategia procesal. Si los tribunales no delimitan de forma clara el contorno de los elementos que componen el orden público y constantemente reconocen nuevos supuestos para conceder la nulidad de un laudo, el orden público terminará destruyendo la razón misma por la que el arbitraje comercial internacional es el mecanismo más utilizado para resolver controversias comerciales a nivel internacional.

\section{F. Evidente}

El tercer principio de interpretación se refiere al nivel de revisión del laudo que es necesario para determinar que éste es contrario al orden público. En este sentido, la doctrina señala que el nivel de revisión emprendido por el juzgador debe ser mínimo.

${ }^{34}$ Cfr. Arfazadeh, H., op. cit., nota 13, p. 50.

${ }^{35}$ Mereminskaya, E., "Eficacia de las sentencias arbitrales internacionales en el derecho ruso y alemán”, en Picand Albónico, E. (coord.), Estudios de Arbitraje, libro homenaje al profesor Patricio Aylwin Azócar, Editorial Jurídica de Chile, Chile, 2007, p. 777.

${ }^{36}$ Cfr. González de Cossío, F., "Orden público y arbitrabilidad: dúo dinámico del arbitraje”, en Revista de Investigaciones Jurídicas, Escuela Libre de Derecho, núm. 32, 2008. 
"La ilegalidad debe saltar a la vista del juzgador. Si es necesario emprender un análisis forzado, exhaustivo, que admite una argumentación alternativa que evadiría la actualización de la causal, no se está en presencia de un auténtico orden público"37.

La facultad de determinar si un laudo es contrario al orden público no autoriza a los tribunales a evaluar el fondo de la controversia. En este momento es útil recordar que por medio del acuerdo arbitral las partes decidieron someter la resolución de la controversia a un tribunal arbitral y no a los tribunales nacionales. Como se ha demostrado en los párrafos anteriores, esta causal de nulidad tiene una justificación clara y delimitada, pero de ninguna forma puede ser la puerta de entrada que le permita a los tribunales revisar la actuación del tribunal arbitral respecto a la forma como resolvió la controversia.

Por lo tanto, para que un laudo sea declarado nulo la contradicción entre éste y el orden público debe ser evidente, esto es, la oposición debe ser obvia con un simple análisis superficial. Adicionalmente, el juzgador debe decidir la cuestión tomando los hechos como fueron demostrados ante el tribunal arbitral. Desde la doctrina se ha señalado que "En la mayoría de las jurisdicciones [donde el arbitraje tiene un nivel importante de desarrollo] hay acuerdo en que la doctrina del orden público no autoriza la revisión del fondo de la decisión del árbitro durante una acción de nulidad” 38 .

\section{Conclusiones}

Como puede observarse, los tribunales nacionales tienen una gran responsabilidad en mantener el concepto de orden público dentro de los límites restringidos que contemplaron los redactores de la Ley Modelo y que son necesarios para el adecuado funcionamiento del arbitraje internacional. En este mismo sentido, en la medida en que los precedentes judiciales demuestren que los tribunales solamente declararán la nulidad de aquellos laudos que claramente sean contrarios a las nociones fundamentales de moralidad y justicia, se reducirán los incentivos para invocar la violación del orden público y tal vez así deje ésta de ser la defensa preferida de quienes se oponen a un laudo.

De lo expuesto anteriormente es posible detectar dos grandes preocupaciones con respecto al orden público como causal de nulidad. En primer lugar, la potencial fuerza expansiva del concepto producto de su vaguedad. En segundo lugar, el potencial riesgo de que, al amparo de esta causal, los tribunales ejerzan un análisis del fondo del laudo. Ambos riesgos son inherentes al concepto de orden público, pero, como se ha señalado, una interpretación restrictiva y una actitud prudente por parte de los tribunales reducen en gran medida estos temores y delimitan al orden público como esa indispensable válvula de escape que garantiza el adecuado funcionamiento del sistema de arbitraje internacional, al evitar dar efectos normativos a aquellos laudos que se encuentren en franca oposición con los principios fundamentales del sistema jurídico.

\footnotetext{
37 Ibídem.

${ }^{38}$ Born, G., op. cit. nota 14, p. 2628. La traducción es nuestra.
} 


\section{BiBLIOGRAFÍA}

Arfazadeh, H., "In the Shadow of the Unruly Horse: International Arbitration and the Public Policy Exception”, en The American Review of International Arbitration, Vol. 13, 2002.

Born, G., International Arbitration. Cases and Materials, Aspen Publishers, EUA, 2011.

Born, G., International Commercial Arbitration, tomo II, Kluwer Law International, Países Bajos, 2009.

González de Cossío, F., Arbitraje, Porrúa, México, 2004.

GonzÁlez de Cossío, F., El arbitraje y la judicatura, Porrúa, México, 2007.

GonzÁlez DE Cossío, F., "Orden público y arbitrabilidad: dúo dinámico del arbitraje”, en Revista de Investigaciones Jurídicas, Escuela Libre de Derecho, núm. 32, 2008.

Mereminskaya, E., “Arbitraje doméstico e internacional en Chile: en búsqueda de la armonía”, en Vargas, J.E. y Gorjón, F.J. (coord.), Arbitraje y Mediación en las Américas, Centro de Estudios de Justicia de las Américas, Universidad Autónoma de Nuevo León, México, 2006.

GonZÁLEZ DE Cossío, F., "Eficacia de las sentencias arbitrales internacionales en el derecho ruso y alemán”, en Picand Albónico, E. (coord.), Estudios de Arbitraje, libro homenaje al profesor Patricio Aylwin Azócar, Editorial Jurídica de Chile, Chile, 2007.

Picand Albónico, E., El arbitraje comercial internacional, tomo I, Editorial Jurídica de Chile, Chile, 2005.

Romero Seguel, A., "Principales diferencias entre el arbitraje interno y el arbitraje internacional en el ordenamiento chileno", en Romero Seguel, A. (coord.), Estudios de derecho en homenaje a Raúl Tavolari Oliveros, LexisNexis, Santiago, 2007.

Romero Seguel, A. y Díaz, J.I., El arbitraje interno y comercial internacional, LexisNexis, Santiago, 2007.

Figueroa Valdés, J.E., "La nueva ley chilena sobe arbitraje comercial internacional”, en Gaceta Jurídica, núm. 303, 2005.

SANDOVAl López, R., "La normativa de Uncitral sobre arbitraje comercial internacional como instrumento de unificación”, en Picand Albónico, E. (coord.), Estudios de Arbitraje, libro homenaje al profesor Patricio Aylwin Azócar, Editorial Jurídica de Chile, Chile, 2007.

SATElER, R., "Historia de la Ley No 19.971 sobre arbitraje comercial internacional", en Picand Albónico, E. (coord.), Estudios de Arbitraje, libro homenaje al profesor Patricio Aylwin Azócar, Editorial Jurídica de Chile, Chile, 2007.

Urrejola Monckeberg, S., "Chile debe contar con una ley de Arbitraje Internacional”, en Boletín Jurídico, Ministerio de Justicia, núm. 6, 2004. 